\title{
Unsaying the said: Emmanuel Levinas and the Zhuangzi on linguistic scepticism
}

Martine Berenpas, Leiden University

\begin{abstract}
In this article I compare the linguistic skepticism of Levinas to that of the early Daoist skepticism of the Zhuangzi. I will argue that both Levinas as the Zhuangzi use skepticism as a therapeutic tool to question the rigid use of language and to create an openness in the self in which the self is inspired by something more than itself. For Levinas, language is primarily a response-ability; language ultimately refers to the absolute responsibility to the Other. For the Zhuangzi, words are simply too rigid to attune to the subtle differences and changes in the world. Through care-free wandering, the self becomes more receptive to the unfolding of the way (Dao).
\end{abstract}

Both the Zhuangzi as Levinas see language not only as a system of references that is able to convey the world, but also see language as communication; as a response to the outside world. For Levinas, this response-ability is aimed at the Other and is primarily an ethical demand. For the Zhuangzi, genuine language is more a spon-taneous receptivity; a wandering with words in which words are open to different interpretations and perspectives. In the end of this article I will argue that Levinas and the Zhuangzi see language as a communicative praxis that mirrors receptivity and passivity.

\section{KEYWORDS}

comparative philosophy communicative

language philosophy of language Emmanuel Levinas Zhuangzi phenomenology

\section{Introduction}

As globalization undeniably continues to change our lives, it is not a surprise that intercultural dialogue has become more and more important to academic research. In philosophy, comparative thinking or intercultural philosophy, is a new dynamic field that faces new opportunities as well as challenges in philosophical explorations. The most important question is why we should compare thinkers separated across time, 
space, culture and language and if and how we can engage in a meaningful comparison (Weber,2014).

In this paper I will explore the possibility of a fruitful comparison between the modern thinker Emmanuel Levinas (1906-1995) and the early Daoist thinker Zhuangzi (late $4^{\text {th }}$ century BC). More particularly, I will compare their use of linguistic skepticism and the way both thinkers use skepticism to point to the limitations of propositional language in favor of a more intuitive language. Both Levinas as Zhuangzi employ skepticism as a method to question the notion of some kind of universal, rational objectivity as the principal aim of thinking. Furthermore, both thinkers point to language as communication and refer to a knack in human action of a praxis that does not effectuate a total closure.

In the first part of the paper, I will discuss Levinas' use of skepticism as proof of the saying that resonates in the said. Levinas sees representation as a type of possession of the subject who can share knowledge with another subject by the common medium of language (Thomas,2004:72). For Levinas, skepticism reminds us of the fact that language is first and foremost a demand to respond to the Otheri. Before language receives its specific content (the Said), it is already addressed to an interlocutor. Language is always primarily a response to the Other, - a responsibility-, which is the source of all signification (the Saying).

For Zhuangzi, skepticism is a therapeutic tool to expose the inherent limitations of language and to question the belief that language adequately conveys the world. Language makes distinctions and discriminations and divides reality in either a "this" or a "that". But, as Zhuangzi argues, by creating such strict ontological borders, we forget to recognize the interrelatedness of things and the ultimate Oneness (Dao) of the world. 
In the second part of my paper, I will compare Levinas' and Zhuangzi's use of skepticism as a method to expose the limitations of (propositional) language. I will argue that both thinkers employ skepticism to reveal the ultimate signification of subjectivity; a signification that reveals an "otherwise than being" that moves away from egoistic aims and purposes. The two thinkers however differ in the way they interpret this ultimate source of signification; for Levinas the origin of signification is the infinite responsibility for the Other, while for Zhuangzi all meaning comes from the spontaneous process of the Way.

At the end of this paper, I will focus on the question how language can signify something otherwise than by signifying a theme and the way both Levinas as Zhuangzi value the unsaying or the beginning-to-say over propositional discourse.

\section{PART I: LEVINAS AND THE ETERNAL RETURN OF SKEPTICISM}

\section{Levinas and the infinite return of skepticism}

Emmanuel Levinas has perhaps more than any other recent thinker, criticized and rethought the ontological primacy of Western metaphysics. As a Lithuanian Jew and a survivor of the Holocaust he argued that the most important problem to philosophy is the question "whether we are duped by morality (Levinas, 2004:11). In his magnus opus Totality and Infinity, - originally published in 1969-,, Levinas argues that Western metaphysics represents a history of violence towards the other insofar as the other is reduced to the same and absorbed by a neutralizing, third term. Levinas reveals the existence of experience that cannot be captured within the "I think"-structure; experience that reveal a "radical alterity" or the "beyond being". 
Especially representational language, argues Levinas, reduces that which is other to something that is cognizable, understandable and thinkable. Representational language, - as ontological thinking-, has the tendency to conceptualize and totalize, bringing that which is other under the umbrella of a third neutralizing term. The Other is for example in Western metaphysics neutralized under the concept of "an animal rationale" or defined as "a divine creature endowed with special rights". The history of philosophy has never acknowledged the uniqueness and the radical singularity of the Other and has as such committed violence to that which is otherwise-than-being (Levinas, 2004:113).

Levinas argues that there are experiences in our lives that cannot be adequately understood in terms of knowledge, representation or conceptualization. Levinas recognizes a "form of intelligibility that goes from the same to the Other without suppressing difference" (Levinas, 1996:6); an experience that touches the subject but at the same time overflows the subject.

Several Levinas scholars such as Standish (2007) Rosato (2014) and Sheikhi (2018), have emphasized the significant role of skepticism as proof for the resonance of the saying in the said. Levinas is drawn to the manner in which skepticism retains meaning despite the fact that it can be shown to refute itself and argues that philosophical skepticism can come up out of the overflowing experience of the otherwise-than-being. Philosophical skepticism is defined by Levinas as the denial of the possibility of all knowledge and which promotes the epistemological claim that "truth cannot be obtained". This radical form of skepticism is a claim in which the objective standpoint undermines itself by the same procedures it uses to call into question, is for Levinas proof that language has an ambiguous and dual nature and can signify something else than its content. 
"Skepticism", writes Levinas at the end of Otherwise than Being (1974), "traverses the rationality or logic of knowledge, [it] is a refusal to synchronize the implicit affirmation contained in saying and the negation which this affirmation states in the said" (Levinas, 1981:171). For Levinas, skepticism is not an attitude, but an essential part of the nature of language because skepticism arises from the tension between the "saying" and the "said".

The distinction between the "saying" and the "said" is intended to capture the double nature of language as on one hand referring to statement, assertion or proposition and on the other hand the communicative nature that reveals the corporeal and sensible exposure of the speaker to the other person (Levinas, 1981; Critchley,2002). This relation to the other is based upon the notion that there is something projective about language; meaning is always open to new development and transcends my usage of language.

For Levinas, the saying is the ethical opening of language that reveals the otherwise-than-being; the experience that meaning can "always open up a passage from the same to the Other, where there is yet nothing in common" (Levinas,1996:6). As Sheikhi puts it aptly, the saying signifies before any fixed meaning, beyond identity and before the establishment of sense and nonsense (Sheikhi, 2018:19).

The said is for Levinas the language of speech and writing; a language guided by knowledge. The said thematizes and classifies the presented phenomena and absorbs the saying by making it static. Levinas argues that as soon as saying becomes part of diction, part of speech, it is immediately dissolved in the said. The saying however leaves an imprint, - a trace-, in the said as a "temporalization which cannot be brought to presence" (Levinas, 1981: 67). Saying leaves an imprint in the said as an attack upon the possibility of all truth claims; as an interruption of essence. The logical form of saying 
exists as a trace in the said and we see this most prominently through the structure of philosophical skepticism, which despite all refutation, keeps returning to mock the "truth" of truth claims.

Levinas speaks of skepticism's "paradoxical presence within our very possession of language" (Levinas, 1998:168). Skepticism is a philosophical practice that interrupts the violence of the said and attests to the ethical demand of the saying.

\section{Skepticism and the demand for a response}

For Levinas, meaning does not only presupposes a world of objects which it articulates, but also presupposes the other to whom it is addressed. Every sentence is, before it is uttered already genuine contact; a relation with a particularity that lies outside the message that it transmits. "Language in its expressive function", argues Levinas:

is addressed to, and invokes the other. It does not consist in invoking him as something represented and thought, but this is just why the distance between the same and the other, in which language occurs, is not reducible to a relation between concepts that limits one another, but describes transcendence, where the other does not weigh on the same, but only places it under an obligation, makes it responsible, that is, makes it speak (Levinas, 1998:41).

In Levinas, the relation to the Other is a pre-intentional relation in which the self is pure response-ability; "a hostage" to the infinite responsibility to the Other. In his alterity, the Other is not recognized, cognized, but answered, by a speaking that is a response.

Discourse is for Levinas not only propositional, but primarily a response-ability that reveals the ethical demand. 
What presents itself as independent of every subjective utterance, is the interlocutor, who is addressed when I speak and to whom I answer through my language. Language attests, - even in speaking to myself-, to the living presence of another person who exposes his being-there to me as an undeniable reality that I cannot reduce to images or ideas in my head (Lis, 2004). Levinas calls this undeniable, ungraspable expression of the other person the "face-to-face-encounter". The face belongs on one hand to the world it inhabits and can be cognized, but on the other hand retains the alterity of a beyond; a transcendence that is inscribed as a trace of radical alterity.

For Levinas, the face of the other is the elementum, the arche, the first principle of interpersonal contact and the origin from which human contact is made possible. This immediate contact classifies Levinas as a "vulnerability" or "nakedness"; it is the immediate recognition as the other as Other human being. Before we are beginning to speak to the other, we are already affected by the Other; we have already recognized him as an interlocutor; as an Other to whom I direct my words. In the presence of the Other, the self recognizes an non-intentional affectivity as having been pre-originally meant for an tied to another (Levinas, 2000:175). The self discovers that it is always a response to the Other; - a responsibility for the Other that exists before any selfconsciousness.

The face-to-face-encounter is described by Levinas in terms of "a traumatism" in which the face of the Other comes from "a height" and "speaks to me", commanding me not to kill him. From the beginning of any face-to-face-encounter, the question of being involves the right to be (Levinas, 1989b:75), which is for Levinas the very origin of moral consciousness. 
For Levinas, it is not my own death that gives meaning to my existence, but the face-to-face-encounter with the Other who questions my freedom and egoistic enjoyment of the world in favor of the existence of the Other (Levinas, 1969:84). Through the face of the Other, we realize the impropriety of our own spontaneity. Through the face of the Other we realize that we are able to annihilate the other in our egoistic spontaneity. The face-to-face encounter is as such the primal experience in which the self is ashamed of its own spontaneity. Levinas says that the face of the Other "traumatizes" the self and raises it to consciousness.

The self is for Levinas a singularity because of the ethical relation to the Other rather than through an ontological event or essence. Singularity as the arising of a responsible person, is not something that can arise out of a single individual; it requires and sustains plurality; it requires interrelatedness and intersubjectivity. For Levinas, the otherwise-than-being means another kind of original ethics; an ethics that arises in sociality and redefines subjectivity as heteronomous instead of homogenous, as an forthe-other instead of a for-itself.

Language is first and foremost a pre-intentional relation to the Other; a response to the Other that involves a responsibility. There is an intertwining of the Other-in-thesame which does not originate from myself but affects me from the side of the Other. In language, this intertwining is the distinction between the "saying" and the "said". The skeptical discourse attests to this fissure, - this plurality-, in language and comes up from the dis-correlation and dis-synchronization between the saying and the said.

Skepticism traverses the rationality or logic of knowledge and is for Levinas a "refusal to synchronize the implicit affirmation contained in saying and the negation which this affirmation states in the said" (Levinas, 1981:168). The contradiction of philosophical skepticism is clearly visible to our thinking, but it seems that skepticism is 
insensitive to its own refutation. Levinas remarks that it seems that "as though skepticism were sensitive to the difference between my exposure without reserve to the other, which is saying, and the exposition or statement of the said in its equilibrium and justice." (Levinas, 1981:172).

Levinas' thinking revolves around the tension in language which on one hand makes representation and thought possible through which the self comes to understand itself, and, - on the other hand-, that language always exceeds the self's understanding and ultimately refers to the relation to the Other.

\section{Language as surplus}

Levinas undertakes to show that language retains a residue of a meta-ontological meaning; a meaning that has an ethical connotation and refers to the Other. The primordial and pre-intentional nature of language is to initiate and sustain communication and to transmit a plea for a response. This plea for a response as response-ability, is the experience of being affected by the face Other who summons me not to kill him and who raises me to consciousness as a individualized and moral subject.

Rather than understanding the ethical as deriving from ontology and which has to originate from a thinking, intentional subject, Levinas stresses the primacy of ethics as a pre-intentional and pre-ontological vulnerability and responsiveness. For Levinas, being only has meaning insofar as its rests on and is based on the ethical relation the Other. It is the absolute obligation to the Other, - the infinite responsibility I have to take him into account-, that precedes and gives significance to every so-called free act. For Levinas, the fundamental meaning of our existence is that I, - and only I-, am always 
responsible for the Other, although I may and can choose not to act upon this responsibility.

This tension between ethics and ontology is also present in language. The trace of the Other is resonated in philosophical skepticism as a truth that speaks of a truth beyond truth, a truth that attests to the infinite responsibility for the Other.

Genuine transcendence is for Levinas not an alienation or distancing from language, but an extraordinary proximity of language which does not collapse into identity, but interrupts language as "the question mark" in being (Levinas, 1996:21). Levinas uses philosophical skepticism as a method to reveal the surplus of language; the fact that human experiences are not exhausted in the capacity of knowing things.

\section{PART II: THE ZHUANGZI AND SKEPTICISM AS A THERAPEUTIC METHOD TO WANDER WITH WORDS}

\section{Zhuangzi's language critique}

The Zhuangzi consists of a variety of parables, riddles, paradoxes and anecdotes that speak of human experiences such as love, life, death and friendship. Yet one thing that stands out in every particular part of the text is its profound critique on language.

As many ancient Chinese thinkers, The Zhuangzi sees language as a social practice that guides action. In the Chinese tradition, language is a social phenomenon that guides human behavior and promotes well-being and harmony (Hansen, 1992:94). Through language we can make distinctions and discriminations towards the perceived phenomena that will help us judge the right or wrong course of action.

In a number of passages, the Zhuangzi appears to be asserting the arbitrariness of judgments and the relativity of the distinctions we make in language. In one passage 
Zhuangzi says: "Words have something to say. But if what they say is not fixed, then do they really say something? Or do they say nothing?" (Zhuangzi, 2009:34).

The Zhuangzi challenges constantly the claim that our general terms can and do represent accurately an independent reality. It is therefore not surprising that many scholars such as Hansen (1992), Kjellberg and Ivanhoe (1996) and Wong (2017) have classified Zhuangzi as a skepticist. Wong for example argues that Zhuangzi endorses a constructive skepticism to "get us to shed our arrogant dispositions to whatever it is that we claim to know" (Wong, 2017:54).

The general tendency of the Zhuangzi is that a lot of human suffering comes from the way we use language as an instrument that categorizes, classifies and interprets reality. People most of the time use words to express and justify human actions and beliefs. Language is used as an instrument to make distinctions between what is "wright" and what is "wrong" and is used to assert universal (moral) truths.

Zhuangzi appears to be concerned with the way language creates strict ontological borders between the presented phenomena and classifies the phenomena as "either a this or a that"(Zhuangzi, 2009:22). Reality, argues Zhuangzi, is however never a "this" or a "that" but far more flexible and ambiguous. When we fail to take this into account, we fail to appreciate the unlimited possibilities of the world and we let ourselves be tied to a limited, rigid perspective.

One of the classic examples in the Zhuangzi that questions the way we use language, is the anecdote of Huizi and the gourd. Zhuangzi's friend Huizi, - a logician-, tells Zhuangzi that the King gave him the seed of a great gourd. He planted it, but when it matured it was so big that Huizi could not use it as either a dipper or a cup. Huizi says to Zhuangzi that: "It was so big and all, but because it was so useless, I finally just smashed it into pieces." (Zhuangzi, 2009,1:13). 
For Huizi, language has tricked him in believing that a gourd is either a dipper or a cup and can be nothing else. Because his language is so fixed, he doesn't see that the gourd can have a new, other meaning.

How is it that you never thought of making it into an enormous vessel for yourself and floating through the lakes and rivers in it? Instead, you worried that it was too big to scoop into anything, which I guess means our greatly esteemed master here still has a lot of tangled weeds clogging up his mind." (Zhuangzi, 2009:1:14)

Huizi saw the gourd as either a "this" or a "that" and wasn't open to new possibilities of what might become new knowledge and insight. When we ascribe meaning to phenomena in a fixed rigid way and isolate phenomena by classifying, naming and interpreting them we, - as Kjellberg and Ivanhoe argue-, "lose sight of the subtle idiosyncrasies that need to be taken into account" (Kjellberg \& Ivanhoe, 1996: xix). Language strives for clear-cut distinctions through exclusion and creating ontological borders, but reality in itself is dynamic and open-ended.

Discriminations and distinctions are only a linguistic outcome to the Zhuangzi, and are not a fundamental characteristic of reality. The fundamental pattern of the world, - referred to in the Zhuangzi as "the Way" or "Dao" (道)-, is the dynamic process that gives rise to the "ten thousand things". Dao is perceived in the Zhuangzi as that which transcends being and is beyond time and space, yet which is present in the world as the ultimate engendering of all things (Chai, 2012).

In terms of language, Dao is surpa-linguistic (Chai, 2012) or pre-linguistic (Ivanhoe, 1996). Stevenson (2006) argues that Dao in the Zhuangzi functions as a sort of 
"background noise" that operates on the margin between language and non-language. This Dao as Oneness that gives rise and actualizes the "ten thousand things" (Zhuangzi, 2009:16) emerges and redefines itself into progressively ordered stages of language or rationality (Stevenson, 2006:305). In all the different things, we however find a "nostalgia" or "trace" of the Oneness of Dao, which means that all things at some point in time, return to Dao.

Although the Zhuangzi clearly employs skepticism to expose the inherent limitations of language and to question our belief that language is able to convey reality, the Zhuangzi does not want us to stop using language. The Dao does not involve an ineffable rejection of language as inevitably dualistic and delusive, but celebrates language as a playfulness and openness that reveals itself when we life more in accordance to Dao.

As Wong notes, the Zhuangzi seeks to remind us that the world is too dynamic and diverse to fit inside the strict ontological borders of language (Wong, 2017:59). For Zhuangzi, the resonance of the Way can only be heard by placing language in context and by keeping in mind the provisionality of our thoughts and language. Through skepticism, the Zhuangzi wants to show us that our language and the meaning we give to phenomena arise out of our unique perspective.

\section{Perspectivism}

For Zhuangzi, the primary concern with language is that we treat meaning as fixed. "Words are like winds and waves", the Zhuangzi remarks and "saying is not blowing breath, saying says something; the only trouble is that what is says is never fixed" (Zhuangzi, 2009:2:51). The Zhuangzi argues that there are no ultimate or permanent 
means for validating the discriminations and categorizations we make in language, for there is no fixed true meaning; the meaning of words vary and change over time.

For Zhuangzi, words do order themselves in discourse, but not according to any rules or conceptual scheme. First of all, words are simply to crude to capture the subtle differences between phenomena or to accommodate to the endless possibilities of reality. As we have seen in the example of Huizi and the gourd, classifications and distinctions often make us blind to other possibilities and prevents us to experience the world as dynamic and constantly changing. Furthermore, the way we use language is the source of constant bickering and discussion, because we try to universalize our moral evaluations. The Zhuangzi's critique is particularly addressed to Confucianism that relies on particular virtues and rituals to cultivate a "good person" (君子). The problem with this kind of reasoning is that we fail to see that what is good for us, might not be good for somebody, - or something-, else.

Through the use of anecdotes, riddles and paradoxes, the Zhuangzi makes us attentive to the fact that we can never know for sure what is right and what is wrong, because all our beliefs, choices and actions are the result of situational and personal circumstances. Inherent in this view is the recognition that judgments are relative to one's unique perspective and that our knowledge of the world is inevitably shaped by our perspective and, as a result, can never be objective or universal.

Zhuangzi's skepticism concerning universal knowledge and his belief that all knowledge is a result of one's perspective, should however not be interpreted in a relativistic way. Although perspectivism is often said to imply relativism, I do not think that the Zhuangzi would argue that all perspectives are equivalent to another. What the Zhuangzi means is that what for one person is right might not be right for another 
person. Furthermore, the Zhuangzi seems to argue that it is particularly our desire to convince others of our right that leads to problems.

Zhuangzi's perspectivism and skepticism are both used as a method to make us more susceptible to the endless possibilities of the Way (道) and refrains us from imposing our unique perspective on that of others: "When everyone keeps their keen vision to themselves", says the Zhuangzi, "the world will no longer be distorted. When everyone keeps their keen hearing to themselves, the world will no longer be confused" (Zhuangzi, 2009:65).

Zhuangzi's perspectivism and skepticism is aimed at exposing the limitations of our beliefs about language and knowledge in favor or a different kind of usage of language and a different kind of knowledge that resonate with the world's dao. Robert Allinson argues that the Zhuangzi aims his linguistic critique on a change in the level of consciousness which "does not depend upon the belief in any system of putative truths", but rather on the silencing of analytical thinking (1989:24). Although Zhuangzi is a skeptic in rejecting the possibility of attaining truth about the world or about values and denies the possibility of objective truth, he is by no means of the opinion that human thinking is unable to live a "truthful life".

Although Zhuangzi rejects disputation that results from the posing and arguing out of alternatives, he speaks favourably of examining and grading thought. The aim of Zhuangzi is encouraging the development of the more intuitive functions of the mind/heart by promoting a willingness to be open to the unfolding of the pattern of the world: "When it came time to arrive, the master did just what the time required. When it came time to go, he followed along with the flow" (Zhuangzi, 2009:24).

\section{Carefree Wandering}


The Zhuangzi seems to argue that our 'inauthentic' attitude to language has its origin in the desire of the senses for completion and possession. The senses such as the ears, eyes and the heart/mind (心ii have the innate desire to fill themselves up with the presented phenomena. The problem with this is that we retain knowledge, judgments and beliefs and hold on to them so eagerly that we fail to respond in a free and open way (Dull, 2011).

We should attune to the unfolding of the Way, which is an attunement to the "coming-into-being"; the attunement to a moment of not yet being a thing but also not the absence of things. For the Zhuangzi, this attunement can be realized by "care-free wandering". In the Zhuangzi, the care for life is not to care for some form in the (transcendental) outer realm, but is aimed at the inner experience of the ceaseless, selfgenerating life of the Way. We should "wander more freely" through life, by letting go any prior knowledge and persisted habits and by adopting a nonassertive, mirroring attitude (wu-wei; 无为).

In the state of $w u$-wei, - an attitude commonly translated as "effortless action" or "non action"-, we engage with the world in a more embodied, skillful way that follows no rules or rituals but is a letting go of oneself so that one can be led by the Way.

Chai (2012) describes the state of wu-wei as a state of "mirroring in which the mind and the body fuse into one and the self comes to possess a form of metaconsciousness through which the internalization of all outward forms of awareness become an ineffable state of experience" (Chai, 2012:83). In the state of wu-wei the homogenous self is thus transformed into a heterogenous self that is affected by something other (or otherwise) than the self.

In the state of wu-wei, the self is "being engendered by Heaven" (Mollgaard, 2007:31), and enables a form of deeper knowledge that makes one more receptive to the 
Way (Chai, 2012:83). Wu-wei appears to open up a new source of power, a "power that generates a flow of energy that exceeds what could be produced by our own strength or actions" (Mollgaard, 2007:40).

Carefree wandering, - or $w u$-wei-, resonates with the coming-into-being of the world and refers to effortlessness, responsiveness and unobstrusiveness. It is however not a technique or a method, but more the simple release of human life into its pure coming-into-being. It is a form of skilled coping with the world (Hansen, 1992), that is aimed at finding peace in whatever the self is encountering and the experience of uniqueness and singularity.

\section{Language as openness}

Zhuangzi's skepticism is aimed against the stability of all language and recognizing the way language approaches reality in a fixed and categorical way that prevents us from moving more freely with the pattern of the Way. Being neither "this" nor "that", we should recognize that the Way always is in-between of that it is and that it is not. In order to let us be more attuned to this "in-betweenness", the first step of the Zhuangzi is to reveals the limitations of language and the recognition that all our beliefs and knowledge are the result of our perspective.

The Zhuangzi argues that we should not give up on language, but we should attune our language to the "in-betweenness" of the Way. This means that we have to find a balance between the tendency of language to create strict ontological borders and to universalize moral evaluation and, on the other hand the message that we want to express. Language is not mere sound, but also not exhausted in meaningful propositions; we should therefore keep language in between saying something and saying nothing. 
The Zhuangzi's use of skepticism and his frequent use of anecdotes, mockery and paradoxes, is a therapeutic method to reveal the limitations of language so that we become open for a more receptive attitude that is more attuned to the unfolding of the Way. Language is used to mark differences, whereas lack of differentiation characterizes the Way. For language to stop hiding the source of all things, it should not be conceived as a closed system, nor as a subjective expressive instrument, but as the concrete and ceaseless flow of utterance produced in communicative interaction between people in specific social and historical circumstances.

\section{The value of philosophical skepticism}

Both Levinas as Zhuangzi employ skepticism as a method to question our common use of language. More particularly, both Zhuangzi as Levinas try to make us through skepticism attentive to the communicative nature of language; to the fact that language refers to our interrelatedness with the world and the other.

For both thinkers, the ultimate form of violence does not seem to be physical, but linguistic; language itself poses the most severe form of violence on all beings. Language covers up things, creates dichotomies and categories things under a third neutralizing term. Zhuangzi and Levinas particularly identify propositional language as violence, due to its tendency to totalize unique and particularized phenomena in a universalized and abstract way.

As a survivor of the Holocaust, Levinas was particular motivated to show that knowledge of the other is an ontology of the same in which the other is comprehended from an object-oriented ontology. Levinas argues that only in ethics do we encounter a reality that cannot contain, thematize, represent or reduce the Other to our own subjectivity. 
For Zhuangzi, words are simply to crude to adequately the dynamic pattern of the Way. Only when we are prepared to let go of fixed beliefs and presupposition and we have no friction whatsoever with our surroundings, we resonate with the Way and we can experience being part of a seamless, easygoing process. For the Zhuangzi, - more than Levinas-, this attitude of $w u$ wei is a fundamental experience with the world as it is an experience of "being at home in the universe".

The Zhuangzi, - in contrast to Levinas-, does not confine man to the social context but situates him in the larger context of ten entire natural cosmos. Levinas however, directs his entire philosophical locus at the relation to the Other. Levinas' revelation of the self that is always already responsible to the Other is more an experience of no longer being at home; it is described by Levinas as a "questioning of my spontaneity" an "ethical command" and is in the end primarily a traumatism or dis-location of the self.. For Levinas, morality begins when freedom, instead of being justified by itself feels itself to be arbitrary and violent.

The most striking similarity however between the two thinkers is that for both Zhuangzi as Levinas, the subject is in the end not homogeneous, but heterogeneous. For Zhuangzi, wu wei leads to a more intuitive and spontaneous self that follows the patterns of the world (Dao). The self is attuned to the world and has a deeper awareness of the interconnectedness and interdependence of phenomena. The self is no longer preoccupied of his own autonomy, but is aware of the "stream of the world" in which he finds his place. For Levinas, it is the relation to the Other that constitutes my subjectivity and gives weight to my existence. Only this relation that is otherwise-than-being ruptures my gratuitous spontaneity and raises me to (ethical) consciousness. Both thinkers seem to define this state of being engendered by a "beyond being" as a passivity that in its passiveness fuels all passivity and activity. Levinas speaks in his work of a 
"passivity more passive than passivity". The break with the egoistic self seems for both thinkers to create an openness through which the self is "more than itself".

Both Levinas and the Zhuangzi use skepticism as a method to allow for a deeper intuition to emerge from within; an intuition that has been obscured by societal linguistic and conceptual schemes. Through linguistic skepticism, the Zhuangzi constantly reminds us to take language not too seriously and to employ language in a playful and elusive manner. Mollgaard (2007) refers to this kind of language as "spillover language" which is a fluid language that keeps its equilibrium through changing meaning and viewpoints (Mollgaard, 2007:14). For Levinas, skepticism attests to our original openness, relatedness and indebtedness to the Other. Although the ethical residue always remains present in propositional language, it seems that Levinas does realize that we will always struggle with our words to reinvent the language of singularity over and against the totality.

Humankind has always struggled to find the right words to express experiences that constitute the most fundamental part of our lives. Through skepticism, both Levinas as Zhuangzi try to show that there are some human experiences that overflow the capacity of propositional language and which are not exhausted in the capacity of knowing things. For both thinkers, language should not be taken primarily as a system of references or as the collective monologue of fitting names and objects, but as a human praxis. Praxis has here the meaning of a process by which a theory, teaching or skill is enacted or embodied.

Through the use of skepticism, we are motivated to return to language as praxis and to understand the constitution of the subject in and through discourse as the potentiality to respond. Genuine subjectivity arises at precisely the point where the full weight of the world is experienced, which is at the same time the recognition that 
intentionality, - where thought remains adequation with the object-, does not define consciousness at its fundamental level.

The skepticism that Levinas and the Zhuangzi embrace, poses inevitably a challenge to philosophy as a foundational, truth-seeking discipline. More particularly, it seems to challenge the theories of meaning based on a doctrine of essence that purchase on the universalizability of meaning through a procedure of representation (Schrag, 2004:4). The rejection of this kind of meaning does however not entail an elimination of knowledge. Both Levinas as Zhuangzi allow for an openness language to emerge that is more intuitive and carries the weight of the world but nevertheless gives us signification and genuine insight.

\section{References}

Allinson, Robert (1989), Chuang-Tzu for Spiritual Transformation: An Analysis of the Inner Chapters, New York: State University of New York.

Chai, David (2012), 'Being, and Dao: Ontology and cosmology in the Zhuangzi', dissertation, Toronto: University of Toronto.

Dull, Carl Joseph (2011), The Zhuangzi and nourishing xin: Causes of strife, positive ideals of caring for living, and therapeutic linguistic practice, Dissertation, Carbondale: Southern Illinois University.

Critchley, Simon (2002), The Cambridge Companion to Levinas, Cambridge: Cambridge University Press 
Hansen, Chad (1992), A Daoist Theory of Chinese Thought: A Philosophical Interpretation, Oxford: Oxford University Press.

Kjellberg, Paul and Ivanhoe, Philip J. (1996), Essays on Skepticism, Relativism, and Ethics in the Zhuangzi, New York: State University of New York Press.

Levinas, Emmanuel (1969), Totality and Infinity: An Essay on Exteriority (trans. Alphonso Lingis), Pittsburgh: Duquesne University Press.

__ (1981), Otherwise than Being or Beyond Essence (trans. Alphonso Lingis), Springer.

------(1989), 'Ethics as first philosophy', in S. Hand, (ed.), The Levinas Reader, Oxford:

Blackwell, pp 75-87.

(1996), Proper Names (trans. Michael B. Smith), London: The Athlone Press.

___ (1998), Collected Philosophical Papers (trans. Alphonso Lingis), Pittsburgh:

Duquesne University Press.

__ (2000), God, Death, and Time (trans. B Bergo), Stanford, CA: Stanford University Press.

Mollgaard, Eske (2007), An Introduction to Daoist Thought, Action, Language, and Ethics in Zhuangzi, Oxon: Routledge. 
Rosato, Jennifer (2015), Levinas on skepticism, moral and otherwise, Philosophy Today, 59 (3), pp. 429-450.

Schrag, Calvin 0. (2004), Convergence amidst Differences: Philosophical Conversations across National Boundaries, New York: State University of New York.

Sheikhi, Sara Alma Safije (2018), Beyond the betrayal of language: On the role of skepticism in Otherwise than Being, Bachelorthesis, Uppsula University.

Standish, Paul (2007), Education for grown-ups, a religion for adults: skepticism and alterity in Cavell and Levinas', Ethics and Education, 2, pp.73-91.

Thomas, Elisabeth Louise (2004), Emmanuel Levinas: Ethics, Justice, and the human beyond being, London/New York: Routledge.

Weber, Paul (2014), Comparative philosophy and the tertium: Comparing what with what, and in what respect?', Dao, a Journal of Comparative Philosophy. 13 (2), pp. 151171.

Wong, David B. (2017), 'Constructive skepticism and being a mirror in the Zhuangzi', Journal of Chinese Philosophy, 44:1\&2, pp. 53-70. 
Zhuangzi (2009), The Essential Writings with Selections from Traditional Commentaries

(trans. Brook Ziporyn), Indianapolis: Hackett Publishing Company Inc.

\section{Contributor details}

Martine Berenpas is a Ph.D. student in comparative philosophy at Leiden University. In her research, she compares Emmanuel Levinas to the early Daoist thinker Zhuangzi. Her research focuses on the question of whether language is able to signify anything else than by signifying a theme. Martine is interested in phenomenology, existentialism and Asian philosophy.

\section{Contact:}

Institute for Philosophy, Leiden University, P.J. Veth building, Nonnensteeg 1-3, 2311 BE Leiden, the Netherlands.

E-mail: m.berenpas@phil.leidenuniv.nl

https://orchid.org/0000-0001-6037-8740

Notes

\footnotetext{
${ }^{\mathrm{i}}$ Levinas writes the "Other" with an uppercase letter when he talks about the ethical relation to the Other. The ontological (empirical) relation between self and the other is written in an lowercase letters.

ii In ancient Chinese philosophy, xin can refer to one's disposition or one's confidence or trust in something or someone. It was generally believed that the heart was the center of human cognition. Due to this reason, xin is commonly translated as the "heart/mind".
} 
